\title{
O agreste virtual: as postagens sobre a novela "Tieta" no perfil oficial do Canal Viva no Facebook
}

\author{
Diego Santos Vieira de Jesus' \\ I - ESPM \\ Rio de Janeiro (RJ), Brasil
}

Resumo: O objetivo é examinar as postagens sobre a novela "Tieta" no perfil oficial do Canal Viva no Facebook e os comentários de seus seguidores. O argumento central aponta que a mobilização de imagens e vídeos de uma personagem empoderada como Tieta alimenta debates na rede social acerca das relações de gênero. Os textos que acompanham o material postado estimulam o público a assumir um papel mais ativo pela internet. Os comentários dos seguidores apontam que a reprise de "Tieta" é um dispositivo de memória da ficção televisiva, que revela campos de embate e negociação em relação a mudanças culturais.

Palavras-chave: Tieta; canal Viva; facebook; telenovela.

\begin{abstract}
The virtual backlands: posts on the soap opera "Tieta" in the Viva Channel official profiles in Facebook - The aim is to examine the posts on the soap opera "Tieta" in Viva Channel's official profile in Facebook and the comments of its followers. The central argument points out that the mobilization of images and videos of an empowered female character like Tieta fuels debates in the social network about gender relations. The texts that follow the posted material stimulate the public to take a more active role through the Internet. The followers' comments point out that the replay of "Tieta" is a memory device of televised fiction that reveals areas of clash and negotiation regarding cultural changes.
\end{abstract}

Keywords: Tieta; Viva Channel ; facebook; soap opera.

\section{Introdução}

Exibida originalmente de agosto de 1989 a março de 1990 na Rede Globo, a telenovela "Tieta" -escrita por Aguinaldo Silva, Ana Maria Moretzsohn e Ricardo Linhares e baseada na obra "Tieta de Agreste", de Jorge Amado- passou a ser reprisada 
no Canal Viva em maio de 2017. A exibição do folhetim rendeu ao canal a liderança do ranking da TV por assinatura em seus dois horários, 15 h30 e 00h15 (AZEVEDO, 2017). A telenovela, que registrou o melhor desempenho de todas já exibidas nas duas faixas, era aguardada ansiosamente pela audiência desde 2010, a estreia do canal, cuja programação é composta predominantemente por telenovelas e programas passados da Rede Globo (RD1, 2017).

A novela, protagonizada por Betty Faria, traz como personagem principal Tieta, que, quando jovem, foi escorraçada da cidade de Santana do Agreste pelo pai. Ele, influenciado pela outra filha, Perpétua (interpretada por Joana Fomm), sentiu-se desonrado com a conduta sexual de Tieta em relação aos homens da cidade. A protagonista seguiu para São Paulo, onde fez fortuna como prostituta e cafetina, e, 25 anos depois, retornou ao agreste disposta a pôr em prática a vingança em relação àqueles que condenavam seu comportamento em nada submisso (ALMEIDA, 2017).

As reprises de telenovelas revelam alterações no fluxo de conteúdos -uma vez que o produto midiático passa a circular novamente- e no comportamento da audiência, que busca na internet uma multiplicidade de interações para debater a narrativa e as ações dos personagens (AQUINO; PUHL, 2011, 40-41). Ao se definir o problema da pesquisa, questiona-se como a nova circulação de um produto midiático de grande popularidade -no caso, a novela "Tieta" no Canal Viva- relaciona-se à busca, pela audiência, de novas formas de interação acerca da narrativa e dos personagens por meio da internet, em particular no perfil oficial do canal numa rede social de grande alcance nacional, o Facebook. Tendo isso em vista, o objetivo do artigo é examinar as postagens sobre a novela "Tieta" no perfil oficial do Canal Viva no Facebook, levando-se em conta o conteúdo das imagens e vídeos postados; os textos que acompanham esse material, elaborados pelos administradores do perfil; e os comentários dos seguidores.

$\mathrm{O}$ argumento central aponta que, num contexto de convergência midiática entre TV e internet, a reexibição de "Tieta" relaciona-se à busca de novas formas de interação pela audiência no perfil oficial do Canal Viva de três formas principais, ligadas ao conteúdo das imagens e dos vídeos postados, aos textos que acompanham esse material e aos comentários dos seguidores. Primeiramente, a mobilização de imagens e vídeos de uma personagem empoderada como Tieta acaba ganhando visibilidade adicional e alimentando debates na rede social em um contexto em que as demandas feministas por respeito nas relações de gênero tornam-se mais disseminadas. Em segundo lugar, os textos que acompanham o material postado estimulam o público a assumir um papel mais ativo pela internet, manifestando opiniões e trocando informações. Finalmente, os comentários dos seguidores apontam que a reprise de "Tieta" é um exemplo de um dispositivo de memória da ficção televisiva, que reativa os sentimentos de identificação do público com a narrativa e os personagens e revela campos de embate e negociação em relação a mudanças culturais. 


\section{Fundamentação teórica}

Como produtos artístico-culturais, as telenovelas operaram no Brasil como agentes de construção de identidade cultural, trazendo "narrativas da nação" -que permitiram revisitar criticamente a ideia de identidade nacional- e recursos comunicativos que criam repertórios compartilhados. Elas são também lugares de memória e documentos de época nos quais representações e imaginários sobre o modo de vida de uma época são depositados e podem ser frequentemente reapropriados (LOPES, 2014, 1-2).

Tais folhetins não promovem interpretações únicas ou consensuais, mas carregam embates pela interpretação de sentidos compartilhados por pessoas de classes sociais, gerações, gêneros, etnias e regiões diferentes, a partir dos quais elas se posicionam e se reconhecem umas às outras. Assim, a telenovela está na base de representações de uma "comunidade imaginada" (ANDERSON, 1991) nacional, permanentemente captada, expressa e renovada pela televisão. Os sentidos sobre a nação produzidos pelas culturas nacionais permitem a identificação das pessoas e constroem suas identidades e estariam presentes em memórias que conectam o passado e o presente da nação e as imagens dela construídas. No caso brasileiro, as telenovelas funcionam como veículos que identificam o Brasil (BUCCl; KEHL, 2004, 222-223). A tematização promovida pela telenovela permite a representação de elementos da identidade nacional. Além de narrar conteúdos, construir tempos sociais e criar sentidos de pertencimento, o folhetim abre caminho para representações às quais diversos indivíduos e grupos podem ter acesso (NEWCOMB, 1999).

Nesse sentido, as telenovelas transcenderam o lazer e se internalizaram na rotina cotidiana, além de terem se definido como experiências culturais, estéticas e sociais. No âmbito da sociabilidade, elas alimentam mecanismos de conversação, compartilhamento e participação imaginária, de forma que os telespectadores se sentem participantes das narrativas e mobilizam informações dos folhetins na sua vida cotidiana. A narrativa audiovisual mostra-se relacionada às inúmeras narrativas presenciais e digitais produzidas pelos telespectadores em torno das tramas (LOPES, 2014, 4). Nesse contexto, a televisão e as ferramentas online mostram convergências, potencializando a visibilidade da telenovela e viabilizando a definição de novos significados em relação à narrativa da trama (AQUINO; PUHL, 2011, 34-35).

Cumpre lembrar que aquilo que é mostrado numa telenovela é baseado na realidade, que, por sua vez, também pode ser alterada pela ficção apresentada (FERNANDES, 2012, 4). Os folhetins televisivos combinam elementos de documentação da realidade com as variações da matriz melodramática, de forma que as tramas, ao terem mais identificações com a realidade, ganhem verossimilhança e legitimidade. Além do estreitamento entre a ficção e a realidade, as telenovelas incorporaram uma dimensão pedagógica, orientando comportamentos e ações, e abriram espaço para a inclusão de novos significados e visões (FIGUEIREDO, 2003).

Ao mesmo tempo, as telenovelas viabilizam aos telespectadores experiências distintas que não apenas entretêm, mas desenvolvem o imaginário coletivo e as memórias 
históricas e afetivas por meio da construção permanente e incessante de sentimentos de pertencimento e de identidade que ancoram a memória de toda a sociedade. As memórias pessoais e coletivas podem surgir ou ser reativadas pelas telenovelas, as quais, ao construírem e resgatarem momentos específicos, são capazes de produzir relações emocionais e afetivas intensas (LOPES, 2014, p.6-9).

Nesse sentido, a telenovela registrou os processos de transformação da própria sociedade brasileira e construiu uma memória ao mesmo tempo documental -em face de sua permanência física como produto audiovisual gravado e sua vinculação com o momento histórico- e coletiva -diante do compartilhamento dos saberes para o público (MOTTER, 2000-2001, 76-77). As reprises de telenovelas -que compõem grande parte da programação do Canal Viva - trazem à tona lembranças associadas a elementos emocionais que compõem a história de vida individual do telespectador. Entretanto, como tais telespectadores têm lembranças construídas a partir de uma base comum, suas memórias apresentam pontos de contato. Ademais, a telenovela permite a documentação de um determinado momento histórico ao armazenar dados sobre tal momento ou período. Assim, ela se configura também como documento de época (LOPES, 2014, 10-15).

Ainda que os telespectadores estejam cientes do caráter ficcional das telenovelas, elas retratam aspectos da vida cotidiana e os costumes sociais, gerando a sensação de proximidade entre esses telespectadores e os personagens e sua identificação com as situações nas quais os últimos estão envolvidos (HAMBURGER, 1998). A proximidade com os personagens e as situações vividas transcendeu as conversas presenciais entre familiares e amigos e hoje ganha espaço na manifestação de opiniões acerca das tramas, pelos telespectadores, nas redes sociais como o Facebook e oTwitter (AQUINO; PUHL, 2011, 36).

Nas reprises das telenovelas, o telespectador passou a exercer um papel mais ativo, identificando na internet uma forma de trocar informações e manifestar opiniões. Mesmo que ele não produza o conteúdo, ele pode repassar e disseminar informação, e a visibilidade das mensagens circuladas torna-se maior (AQUINO; PUHL, 2011, 40-43). Mesmo sem compartilharem o mesmo espaço, os espectadores adquirem maior visibilidade a partir da multiplicidade de tecnologias digitais, as quais ampliaram o fluxo de conteúdo pelas redes, ofereceram a esses espectadores maior liberdade para criar e disseminar conteúdos a um número maior de pessoas e permitiram a eles assistir ao conteúdo televisivo e simultaneamente interagir com outros espectadores na rede (THOMPSON, 2008).

Diante da maior proximidade entre os meios de comunicação de massa e a internet num contexto de modificações sociais, tecnológicas e mercadológicas, a ideia de "convergência midiática" engloba múltiplos tipos de confluências, como a ampliação de fluxo de conteúdos e informações em suportes midiáticos diversificados, a cooperação entre tais suportes e seus respectivos mercados e a migração constante dos públicos entre os meios de comunicação na procura de novas experiências de lazer e de entretenimento (JENKINS, 2008, 27). A emergência de uma cultura cada vez mais participativa conduziu 
ao uso de diversas plataformas pelos telespectadores na busca de espaços variados de manifestação de opiniões, de intercâmbio de informações e de produção de conteúdo. As características dessa produção e da transmissão de tal conteúdo variam entre os meios e as plataformas (AQUINO; PUHL, 2011, 41).

Reconhecendo-se a especificidade da convergência da TV com o Facebook, podese falar da possibilidade de utilização de imagens e trechos de vídeos veiculados na TV em postagens na rede social; a inserção de textos e mensagens nessas mensagens, que se relacionem ao conteúdo da obra televisiva; e os comentários feitos por usuários, nos quais se explicitam os diferentes modos de recepção do conteúdo disponibilizado na TV e posteriormente inserido nas postagens no Facebook. Em face disso, pode-se compreender a construção das categorias de análise deste estudo do material acerca de "Tieta", postado no perfil do Canal Viva no Facebook: o conteúdo das imagens e vídeos, os textos das postagens no perfil e os comentários dos seguidores. Tais categorias foram mobilizadas na sistematização dos resultados, como se verá adiante.

\section{Considerações metodológicas}

Na primeira etapa da pesquisa, foi realizado um levantamento bibliográfico acerca do papel da telenovela na construção de identidade e da convergência entre os meios de comunicação. O objetivo foi tecer o suporte teórico-conceitual para a análise a ser desenvolvida. Foi executada, na coleta de dados, uma pesquisa documental que levou em conta, no perfil do Canal Viva no Facebook, 50 postagens referentes à novela "Tieta" e ao seu elenco de fevereiro a julho de 2017. Embora a novela tenha começado a ser reexibida em maio de tal ano, a notícia de que "Tieta" substituiria "A Gata Comeu" foi anunciada em fevereiro no perfil do canal. A seleção dos itens da amostra foi feita com base nos seguintes critérios: 1) as postagens precisavam conter exclusivamente conteúdo relacionado à telenovela "Tieta" e aos seus personagens, sem qualquer relação com outras produções transmitidas pelo Canal Viva; 2) esses posts deviam ter, no mínimo, 50 comentários de usuários; 3) tal número mínimo de comentários teve que ser atingido ao longo de uma semana após a postagem desse conteúdo, o que aponta para um interesse contínuo no tópico ali apresentado. A identificação da data em que esse número mínimo foi atingido foi feita a partir da verificação das datas em que os comentários foram realizados. A amostra de 50 postagens representa cerca de 53,76\% do total de posts (93) acerca da novela e de seus personagens no perfil do Canal Viva até o momento de término da pesquisa. Os objetivos foram 1) captar mais precisamente as percepções e as memórias referentes unicamente à novela em foco; 2) selecionar o material textual e visual produzido pelo administrador do perfil no Facebook e pelos telespectadores da novela que comentaram nas postagens - a partir do qual se pretende examinar a interação entre o produto cultural veiculado na televisão e as discussões numa das principais redes sociais 
utilizadas por brasileiros, mais especificamente no perfil do próprio canal que reprisa a telenovela. Todos os elementos examinados -vídeos / imagens, texto das postagens e comentários- estiveram presentes nos itens da amostra selecionada.

$\mathrm{Na}$ análise dos dados, procurou-se descrever e interpretar qualitativamente o conteúdo da classe de documentos, no caso das postagens no Facebook. Parte-se de uma base teórico-conceitual, que, no exame do documento, serve de suporte para captar seu sentido simbólico (VERGARA, 2012, 7-17). O material textual e visual coletado foi agrupado em três categorias: o conteúdo das imagens e vídeos postados, os textos elaborados pelos administradores do perfil que acompanham esse material e os comentários dos seguidores do perfil nas postagens. Os comentários foram considerados na análise tendo em vista sua relevância na compreensão dos modos de recepção do conteúdo apresentado nos posts. A seguir, para cada uma das categorias, produziu-se a descrição dos resultados, que expressa o conjunto de significados presentes. Finalmente, tais resultados foram interpretados a partir uma exploração dos significados expressos em contraste com a fundamentação teórica.

\section{Resultados}

\section{O conteúdo das imagens e dos vídeos}

As imagens utilizadas pelo perfil do Canal Viva tiveram predominantemente o formato de memes, um conceito de imagem -em geral, acompanhada de algum texto- relacionado ao humor que se propaga pela internet (cerca de $6 \%$ da amostra de 50 posts). Na postagem de fevereiro de 2017 em que o Canal Viva anunciava que reprisaria "Tieta", aparece a imagem da personagem Perpétua com expressão de surpresa, acompanhada do texto

"Eu quando soube que vai ter Tieta no Viva". Em postagem posterior do mesmo mês, uma imagem exibe Betty Faria altiva, coberta de joias, interpretando Tieta, com a mensagem "Novela boa não fica velha". Outro meme traz "Eu <3 Tieta" com imagens da novela ao fundo e o anúncio da maratona de capítulos da novela, exibidos durante a semana e reprisados aos domingos a partir das 19h. Além dos memes, fotos que mostram atores e atrizes do elenco na época de exibição original da novela e nos dias atuais de forma comparativa também foram postadas, como as imagens de Joana Fomm interpretando Perpétua e da atriz nos dias de hoje numa publicação de fevereiro de 2017 (4\% da amostra). Outras fotografias trazem imagens atuais de membros do elenco da novela em comemoração aos seus aniversários, como os posts de maio que celebram os aniversários de Betty Faria e Luiza Tomé, que interpretara na novela Carol, amante do poderoso Modesto Pires (personagem de Armando Bógus), o que representa 4\% da amostra.

Os vídeos em geral traziam resumos com pequenos trechos mais importantes dos capítulos que seriam exibidos naquela semana ou foram exibidos na anterior ou apresentavam momentos emblemáticos da trama, como o retorno de Tieta a Santana 
do Agreste; os ataques da "mulher de branco", uma assombração que vagava pela cidade, aos homens; e os momentos de intimidade entre Tieta e seu sobrinho, o seminarista Ricardo (interpretado por Cassio Gabus Mendes), por quem ela se apaixona ao longo da trama. Todos os vídeos foram postados a partir de maio de 2017. Os vídeos que representam esses momentos decisivos da narrativa, envolvendo ações dos protagonistas, representam $50 \%$ das postagens selecionadas. Outros vídeos retratam discussões entre outros personagens, como o idealista Ascânio (vivido por Reginaldo Faria), que sonha com o progresso para Santana do Agreste, e o comandante Dário (interpretado por Flávio Galvão), que almeja preservar o meio ambiente e a vida pacata da cidade. Os vídeos também trazem momentos cômicos protagonizados por personagens como Perpétua e o padre Mariano (interpretado por Claudio Corrêa e Castro) ou partes em que alguns personagens aparecem falando seus bordões, como Dona Milu (interpretada por Miriam Pires) e seu bordão "Mistééééério!". Eles representam $36 \%$ do total da amostra selecionada.

\section{Os textos das postagens}

Os textos das postagens que acompanham as imagens e os vídeos, elaborados pelo administrador do perfil, vieram, em sua totalidade, acompanhados da hashtag \#TietaNoViva, que funcionam como indexadores na rede social. A grande maioria desses textos carregava opiniões em relação às ações dos personagens nas imagens e nos trechos dos vídeos postados, como demonstrações de solidariedade, pena ou amizade e provocações a eles (80\% da amostra). Por exemplo, em julho de 2017, o vídeo em que Ricardo confessa ao padre Mariano que havia tido relações afetivas com uma mulher (no caso, sua tia) veio acompanhado do comentário "Aiii, tadinho do Ricardo!". No mesmo mês, um vídeo em que Ascânio aparece expulsando de casa a ex-mulher Helena (interpretada por Françoise Forton) vem junto ao comentário "Está aberta a temporada do barraco!", com emojis de revólver, soco e bomba, em referência à expressão "Tiro, porrada e bomba".

Além do uso da linguagem mais coloquial e informal nas postagens pelo administrador do perfil, houve também uma grande utilização de emojis que expressavam sensações de espanto, fúria, alegria -em especial a gargalhada- e amor. Outros textos reproduziam a fala dos personagens, como o texto que acompanha o vídeo de julho de 2017, que retrata o personagem Arthur da Tapitanga (interpretado por Ary Fontoura) desconfiando que suas "rolinhas" (meninas a quem oferecia abrigo e comida em troca de favores sexuais) estavam tramando algo: "Coronel tá desconfiaaaado!". Num post que apresenta os capítulos da semana de 10 a 14 de julho de 2017, o texto traz marcas do linguajar regional: "Vem mais uma semana arretada por aí!".

Outros textos traziam estímulos para a realização de comentários dos telespectadores e a manifestação de suas opiniões sobre temas levantados nas cenas retratadas, o que 
representa 10\% das postagens selecionadas. Numa postagem de junho de 2017, o vídeo traz Ricardo confessando seu amor a Tieta e seu desejo de deixar o seminário para se casar com ela. O texto que acompanha o vídeo vem com o comentário: "Segura essa, Brasil! Diz aí: você é a favor ou contra o casamento?" Em uma postagem do mesmo mês, o vídeo mostra Ascânio tirando da mão de Helena a carta do amante dela, e o texto diz: "Sujou pra você, Helena! Quem aí tá feliz?"

Já outros convidam os telespectadores a acessarem outros recursos online relacionados à novela. O post de fevereiro de 2017 com a foto antiga e a recente de Joana Fomm traz a pergunta "Lembra dos atores de \#Tieta?" e um link para o site do canal, no qual se vê o antes e o depois dos atores principais do elenco. Outro post do mesmo mês traz um trecho da música-tema de abertura da novela, cantada por Luiz Caldas, e um convite para que o telespectador relembre a trilha sonora acessando um link para uma playlist com tais canções no serviço de streaming Spotify. Postagens nesse perfil representam os $10 \%$ restantes da amostra.

\section{Os comentários dos seguidores}

Na amostra selecionada, até o momento de finalização da pesquisa, haviam sido realizados cerca de 5600 comentários por seguidores nas postagens. A maior parte dos comentários feitos pelos seguidores do perfil do Canal Viva é elogioso à novela e ao seu elenco, o que representa aproximadamente $86 \%$ desse número de comentários. "A melhor novela de todos os tempos. Nunca mais uma novela unirá nomes de peso", disse um seguidor em um post de fevereiro de 2017. Em postagens em que Betty Faria e Joana Fomm são destacadas, elas são frequentemente saudadas pelo seu talento e chamadas de "divas", mesmo quando esses telespectadores classificam a personagem Perpétua de "xexelenta", "tribufu" ou "bacalhau seco", repetindo xingamentos que ela recebe na trama por outros personagens. Há comentários que relembram a época da exibição original da novela na Rede Globo de maneira afetuosa. "E a trilha sonora? Volto aos bons tempos da minha préadolescência!", disse uma seguidora em uma postagem de julho de 2017. Comentários nesse estilo são realizados não apenas com referência aos personagens, mas também aos locais exibidos e às roupas e aos acessórios utilizados. Internautas também revelam a saudade em relação a atores já falecidos, como Armando Bógus, Elias Gleizer, Claudio Correa e Castro e Miriam Pires, e pedem que outros voltem a atuar, como Lidia Brondi.

Alguns telespectadores revelam seu envolvimento claro com a narrativa a ponto de conversarem com os personagens e se imaginarem nas situações retratadas. Por exemplo, em um vídeo postado em julho de 2017 que mostra a chegada de Rosalvo (Paulo César Grande) e Bebê (Simone Carvalho) a Santana do Agreste de ultraleve, um seguidor comentou "Pelo jeito, boa coisa não é a chegada desse povinho aí no Agreste!", como se fosse moradora do local. Num resumo dos capítulos semanais apresentados em vídeo 
no mesmo mês, uma seguidora coloca "Abre o olho, Timóteo [personagem de Paulo Betti]! Vc só fica pensando no estômago e Elisa [interpretada por Tássia Camargo] pensando em outra coisa".

Alguns telespectadores oferecem spoilers, contando a sequência dos acontecimentos nos capítulos seguintes, e outros se queixam do horário de transmissão pelo Canal Viva: "Que delícia de novela!! Não perco a maratona. Pena que na semana é muito tarde". Nas postagens com conteúdo mais controverso ou polêmico, instauram-se debates que giram em torno de valores e identidades dos personagens ou de situações em que se veem diante de dilemas pessoais. Na postagem com o vídeo em que Ricardo confessa ao padre Mariano "ter conhecido mulher", uma telespectadora comentou "Gente, a novela é muito boa, a tia transar com o próprio sobrinho é a treva. Meu Deus...". Até julho de 2017, o comentário continha 51 respostas, a maior parte criticando a observação feita. Nessa mesma postagem, outra seguidora comentou "Acho o Padre compreensivo com Cardo, diferente de Cosme [personagem de Paulo Nigri], a bicha apaixonada e obcecada". Oito das 21 respostas faziam chacota da suposta homossexualidade de Cosme e defendiam a heterossexualidade de Ricardo, enquanto outros condenavam o comentário da seguidora como "homofóbico".

\section{Discussão e análise}

A telenovela "Tieta" é uma adaptação da obra "Tieta do Agreste", de Jorge Amado, que também teve uma versão para o cinema em 1996 sob a direção de Cacá Diegues. Ainda que na adaptação televisiva a sensualidade da protagonista não seja tão explícita como no livro e no filme, Tieta é colocada como dona de seu destino e de sua vida sexual, chegando mesmo a desafiar valores familiares e morais. Já uma mulher madura, ela seduz um rapaz, que, além de manter uma diferença de idade em relação a ela, possui com ela também laços de sangue. Num cenário poético e pitoresco, isolado no coração do agreste, Tieta apresenta desvios de conduta em relação à sociedade em que estava inserida (SILVA, 2012, 44-45). O caráter altivo e empoderado da personagem é ressaltado nas imagens e nos vídeos postados pelo perfil do Canal Viva, que evidenciam não apenas a boa forma de Betty Faria quando protagonizou a novela, mas o vigor e a determinação de sua personagem. A ideia de uma mulher empoderada e dona de si acaba ganhando visibilidade adicional na reprise da novela e alimentando debates sociais em um novo contexto em que as demandas feministas por respeito nas relações de gênero tornamse mais disseminadas, inclusive pelas novas tecnologias. Tais temas foram abordados predominantemente nos vídeos, que representam $86 \%$ do material apresentado nos posts considerados na amostra.

Se por um lado Tieta era objeto de desejo dos homens, ela também se coloca como capaz de ter desejos e força para realizá-los, contrariando o que era esperado quanto 
à posição da mulher numa sociedade patriarcal e conquistando novos espaços não mais limitados ao ambiente familiar. À frente do seu tempo e em oposição ao seu meio, Tieta envolvia-se inclusive na política de uma cidade claramente marcada pelo conservadorismo e pelo patriarcalismo (COELHO et al., 2014, 128-131). Outras personagens da trama como Tonha (interpretada por Yoná Magalhães), a apagada mulher do pastor Zé Esteves (vivido por Sebastião Vasconcelos), foram recriadas de maneira exuberante na telenovela e reforçaram a empatia do público. A novela também inseriu fatos e situações que não existiam na obra original de Jorge Amado, como os mistérios da "mulher de branco" e da "caixa branca de Perpétua", que marcaram o imaginário da população brasileira (BESSA, 1990, 67-68). Os textos que acompanham as postagens de imagens e vídeos sobre a novela no perfil oficial do Canal Viva no Facebook estimulam o público a assumir um papel mais ativo, manifestando opiniões e trocando informações. Enquanto, na maioria dos posts, o perfil do canal o faz se posicionando acerca das ações dos personagens (80\%), em outros ele estimula explicitamente o debate (10\%). Esse público pode repassar e disseminar informação, conferindo uma visibilidade maior para as mensagens circuladas. A proximidade que o administrador do perfil oficial do canal constrói com o público a partir dos textos dá-se, no caso de "Tieta", de múltiplas formas: o uso de linguagem coloquial e emojis que se aproximam das formas de comunicação dos seguidores, a reprodução das falas dos personagens, o estímulo ao debate sobre temas controversos e a mobilização de outras plataformas para ampliar a experiência do telespectador com a novela, como o site do canal e os serviços de streaming.

Como se percebe nos comentários dos seguidores, ainda que o talento de todo o elenco seja reconhecido e venerado, vê-se que, como no momento da exibição original da trama, os personagens de "Tieta" que despertam menos simpatia do público são os que procuram exercer domínio e poder por meio de agressões e chantagens -como Perpétua e o coronel Arthur da Tapitanga-, enquanto os que despertam mais simpatia buscam o bem-estar e a proteção dos outros, como Tieta, Tonha e Carmosina (personagem de Arlete Salles) (CAMINO et al., 1994). Como discutido anteriormente, a reprise da telenovela pelo Canal Viva é um exemplo de um dispositivo de memória da ficção televisiva, que reativa os sentimentos de identificação do público com a narrativa e os personagens. Uma audiência mais jovem pode assistir à telenovela pela primeira vez, enquanto adultos podem revê-la (LOPES, 2014). Constrói-se, assim, uma rede de memórias de tempos passados e presentes e de idades passadas e presentes. Isso ocorre tanto ao se ver como eram no passado atores e atrizes, quanto ao se constatar como a ficção era feita no passado; tanto ao se recordar um tempo da própria vida quando se assistiu à ficção original quanto ao sentimento de ver a sua reprise atualmente (LOPES et al., 2002). Os comentários dos seguidores revelam essa relação afetiva intensa não só com a narrativa e os personagens, mas a época original em que a novela foi transmitida e os próprios atores.

Mais do que funcionar como um repertório comum ao diálogo, a telenovela atua como um elemento de rememoração e de documentação de um determinado momento 
histórico, armazenando dados sobre certa temporalidade. Além de um documento de época, a telenovela também se confirma como um repositório de marcas de mudanças culturais e de construção e arquivamento da memória coletiva (LOPES, 2014, 15). Comentários dos seguidores feitos nas postagens no perfil oficial do Canal Viva sobre "Tieta" revelam campos de embate, negociação, conflito e conciliação em relação a essas mudanças, que se manifestam posturas mais progressistas ou conservadoras dos telespectadores em tensão permanente na definição da memória coletiva.

\section{Considerações finais}

A adaptação de obras literárias para a TV era concebida como um meio de divulgação de obras e autores consagrados. Com o desenvolvimento de uma linguagem própria televisiva, a relação das telenovelas com as obras literárias tornou-se mais complexa e multifacetada (GOMES, 2009, 95). Com a convergência cada vez maior da TV com a internet, os fluxos de conteúdo televisivo passam a acontecer a partir de diversos suportes midiáticos, os diferentes mercados de mídia se comunicam e cooperam entre eles, e os públicos migram entre os meios de comunicação em busca de novas experiências de entretenimento desejadas (JENKINS, 2008, 26-28). Tem-se, assim, mais uma transformação no consumo da telenovela como produto artístico-cultural, muitas vezes adaptado de uma obra literária como é o caso de "Tieta". O público passa a ter um papel muito mais ativo e cria, a partir das narrativas originais e adaptadas, inúmeras novas interpretações e desenvolve experiências alternativas no seu envolvimento com as narrativas.

Ao ter contato com uma produção televisiva de arquivo, o indivíduo, que traz consigo seu próprio repertório e imaginário, expõe-se a um produto de memória televisiva com elementos do passado e gera um novo processo de interação, como comprova a reexibição de "Tieta". Ao revisitar o passado, o sujeito assume a identidade de reciclador de sua própria identidade, que terá reflexo na identidade nacional. Na contemporaneidade, a possibilidade de repercussão das narrativas e dos personagens pelas redes sociais gera, assim, uma multiplicidade de cenários alternativos de mediação e de experiências com os folhetins (FERNANDES, 2012, 10).

Diego Santos Vieira de Jesus é pesquisador e professor do Programa de Mestrado Profissional em Gestão da Economia Criativa (MPGEC) e professor dos cursos de Graduação em Administração de Empresas, em Comunicação Social da ESPM-Rio. É doutor em Relações Internacionais pelo Instituto de Relações Internacionais da PUC-Rio. É membro do Laboratório de Cidades Criativas (LCC) da mesma instituição.

dvieira@espm.br 


\section{Referências}

ALMEIDA, F. Tieta deixa Canal Viva na liderança da TV paga. O Fuxico, 8 jul.2017. Disponível em: http://www.ofuxico.com.br/noticias-sobre-famosos/tieta-deixa-canal-viva-na-lideranca-da-tvpaga/2017/07/08-297922.html. (Acesso em 9 jul. 2017)

ANDERSON, B. Imagined Communities. Londres: Verso, 1991.

AQUINO, M. C.; PUHL, P. Vale tudo no Twitter: a visibilidade da ficção televisiva em tempos de convergência midiática. Alceu, v.12, n.23, p.34-48, jul/dez 2011.

AZEVEDO, P. Tieta supera todas as novelas do Viva e bate recorde na internet. Observatório da Televisão, 8 jul. 2017. Disponível em: https://observatoriodatelevisao.bol.uol.com.br/audiencia-datv/2017/07/tieta-supera-todas-as-novelas-do-viva-e-bate-recorde-na-internet. (Acessado em 9 jul.2017)

BESSA, P. P. Tieta - Telenovela. Letras, n. 39, p. 63-71, 1990.

BUCCI, E.; KEHL, M. R. Videologias: ensaios sobre televisão. São Paulo: Boitempo, 2004.

CAMINO, C. S; BATISTA, L.; REIS, R.; RIQUE NETO, J.; LUNA, V.; CAVALCANTI, M. das G. A transmissão de valores morais em personagens de TV. Psicologia: reflexão e crítica, v. 7, n. 1, p. 29-46, jan/jun 1994.

COELHO, P. F., RANGEL, P. L. N., SILVA, C. da C. In: III Congresso Internacional Interdisciplinar Em Ciências Sociais E Humanidades. Anais... Salvador, 8-10 out. 2014, p.120-133.

FERNANDES, J. C. Memória televisiva na construção do imaginário nacional: estudo da reexibição da telenovela "Vale Tudo" no Canal Viva. In: XVII Congresso De Ciências Da Comunicação Na Região Sudeste. Anais... Ouro Preto, 28-30 jun. 2012.

FIGUEIREDO, A. M. Teledramaturgia brasileira: arte ou espetáculo? São Paulo: Paulus, 2003.

GOMES, M. O intertexto midiático: ficção seriada televisiva e adaptação de obras literárias: as ideias no fluxo das mídias. Conexão - Comunicação e Cultura, v. 8, n. 15, jan/jun 2009.

HAMBURGER, E. O Brasil antenado: a sociedade da novela. Rio de Janeiro: Ed. Jorge Zahar, 2005.

JENKINS, H. Cultura da convergência. São Paulo: Editora Aleph, 2008.

LOPES, M. I. V. de. Memória e Identidade na Telenovela Brasileira. In: XXIII ENCONTRO ANUAL DA COMPÓS. Anais... UFPA. Belém, 27-30 maio 2014.

; BORELLI, Silvia Helena Simões; RESENDE, Vera da Rocha. Vivendo com a telenovela. Mediações, recepção e teleficcionalidade. São Paulo: Summus, 2002.

MOTTER, M. L. A Telenovela: Documento Histórico e Lugar de Memória. Revista USP, n.48, p.7487, 2000-2001.

NEWCOMB, H. La Televisione da Forum a Biblioteca. Milão: Sansoni, 1999.

RD1. "Tieta" leva Viva à liderança da TV por assinatura; novela bomba em aplicativo on-demand. RD1 website, 8 jul.2017. Disponível em: https://rd1 .com.br/tieta-leva-viva-lideranca-da-tv-por-assinaturanovela-bomba-em-aplicativo-on-demand/. (Acessado em 9 jul.2017)

SILVA, E. V. da. Quem dá as ordens? A Imagem Transnacional da Mulher Brasileira em Dona Flor, Gabriela e Tieta. Transnationality in the Luso-Hispanic World, p.33-49, 2012.

THOMPSON, J. B. A nova visibilidade. Matrizes, Ano 1, n.2, p.15-38, jan/jun 2008.

VERGARA, S. Métodos de pesquisa em Administração. São Paulo: Atlas, 2012. 